\title{
Cocaine and metabolites in waste and surface water across Belgium
}

\author{
Alexander L.N. van Nuijs ${ }^{\mathrm{a}, *}$, Bert Pecceu ${ }^{\mathrm{b}}$, Laetitia Theunis ${ }^{\mathrm{c}}$, Nathalie Dubois ${ }^{\mathrm{c}}$, Corinne Charlier $^{\mathrm{c}}$, \\ Philippe G. Jorens ${ }^{\mathrm{d}}$, Lieven Bervoets ${ }^{\mathrm{b}}$, Ronny Blust ${ }^{\mathrm{b}}$, Hugo Neels ${ }^{\mathrm{a}, \mathrm{e}}$, Adrian Covaci ${ }^{\mathrm{a}, \mathrm{b}}$ \\ ${ }^{a}$ Toxicological Centre, Department of Pharmaceutical Sciences, University of Antwerp (UA), Universiteitsplein 1, 2610 Antwerp, Belgium \\ ${ }^{\mathrm{b}}$ Laboratory for Ecophysiology, Biochemistry and Toxicology, Department of Biology, University of Antwerp (UA), Groenenborgerlaan 171, 2020 Antwerp, Belgium \\ ${ }^{c}$ Laboratory of Clinical, Forensic and Environmental Toxicology, University of Liège, (ULg), CHU Sart-Tilman, 4000 Liège, Belgium \\ ${ }^{\mathrm{d}}$ Department of Clinical Pharmacology/Clinical Toxicology, University of Antwerp (UA), University Hospital of Antwerp, Universiteitsplein 1, 2610 Antwerp, Belgium \\ ${ }^{\mathrm{e}}$ Laboratory of Toxicology, ZNA Stuivenberg, Lange Beeldekensstraat 267, 2060 Antwerp, Belgium
}

Cocaine consumption can be evaluated through analysis of waste and surface water.

\section{A R T I C L E I N F O}

\section{Article history:}

Received 9 June 2008

Received in revised form 8 July 2008

Accepted 24 July 2008

\section{Keywords:}

Cocaine

Waste water

Surface water

Cocaine equivalents

Cocaine consumption

LC-MS

\begin{abstract}
A B S T R A C T
Cocaine abuse, a growing social problem, is currently estimated from population surveys, consumer interviews and crime statistics. A new approach based on the analysis of cocaine (COC) and metabolites, benzoylecgonine (BE) and ecgonine methyl ester (EME), in water samples was applied to 28 rivers and 37 waste water treatment plants in Belgium using solid-phase extraction and liquid chromatography coupled to tandem mass spectrometry. While EME was undetectable, COC and BE were detectable with concentrations ranging from $<1$ to $753 \mathrm{ng} / \mathrm{L}$ and $<1$ to $2258 \mathrm{ng} / \mathrm{L}$, respectively. BE concentrations were employed to calculate the local amount of abused cocaine. The highest values (up to $1.8 \mathrm{~g} /$ day cocaine per 1000 inhabitants) were found in large cities and during weekends. The estimation of cocaine abuse through water analysis can be executed on regular basis without cooperation of patients. It also gives clear geographical information, while prevention campaigns can easily be implemented and evaluated.

(c) 2008 Elsevier Ltd. All rights reserved.
\end{abstract}

\section{Introduction}

Abuse of illicit drugs is a major problem in our contemporary society. The consumption of drugs leads not only to a high mortality and morbidity, but also to many socio-economic problems (economic damage, criminality, social insolation, a.s.o.). The European Monitoring Centre for Drugs and Drug Addiction (EMCDDA) estimates that even $4 \%$ of the European adults (approximately 12 million people) has used cocaine (COC) during their lifetime, and that 3 million European adults have used cocaine in 2007 (EMCDDA, 2007). The EMCDDA observed, after a stabilizing trend in 2006, an obvious increase in cocaine consumption during 2007. This explains why cocaine abuse seems to be a growing problem in Europe and a major issue for the European drug policy. By comparison, a stabilizing and even decreasing trend for the consumption of other drugs such as ecstasy and cannabis has been observed (EMCDDA, 2007), probably as a consequence of their replacement by cocaine. A decrease in the cocaine price could be another explanation. These trends in drug abuse are estimated indirectly from population surveys, consumer interviews,

\footnotetext{
* Corresponding author. Tel.: +32 3820 2743; fax: +32 38202722.

E-mail address: alexander.vannuijs@ua.ac.be (A.L.N. van Nuijs).
}

individual medical records and crime statistics (EMCDDA, 2002). Such general indicators can give only raw estimations of drug abuse, but accurate and local measurements are not possible with this approach (Zuccato et al., 2005). Also in Belgium, limited information is available about the cocaine abuse (Lamkaddem and Roelands, 2007).

Cocaine is still administered as topical anesthetic compound in intranasal, ophthalmologic and bronchoscopic procedures (Dart, 2004). Illegally, cocaine is used by intranasal ("snorting"), intravenous or smoking routes (Cone, 1995). It has three important actions in humans: direct blocking of fast sodium channels, interfering with the uptake of neurotransmitters such as epinephrine and dopamine and a vasoconstrictive action (Dart, 2004). The use of cocaine has direct physiological effects on humans, such as central nervous system over-stimulation, risk of heart attack, pulmonary complications and altered serotonin levels (Lakoski et al., 1991). In humans, COC is rapidly hydrolyzed to benzoylecgonine (BE) and ecgonine methyl ester (EME) and some minor metabolites (Dart, 2004). Only a small fraction of COC is excreted in urine as parent compound, while the largest amount is excreted as $\mathrm{BE}$, the most important metabolite, and EME (Ambre et al., 1984, 1988). In urine, COC can be detected for approximately $8 \mathrm{~h}$, while BE and EME can be positively identified for more than $96 \mathrm{~h}$ (Hamilton et al., 1977; Jufer et al., 2000). 
Recently, a new, direct and objective way of monitoring drug consumption has been proposed, based on the measurement of urinary excreted drugs and their metabolites in waste and surface water (Bones et al., 2007; Castiglioni et al., 2006; Gheorghe et al., 2008; Huerta-Fontela et al., 2007; Hummel et al., 2006; KasprzykHordern et al., 2008a,b; Zuccato et al., 2005, 2008). While these studies are particularly based on measurements by liquid chromatography coupled to tandem mass spectrometry (LC-MS/MS), they differ on the sample preparation approaches and the groups of investigated drugs of abuse.

In the present study, a previously optimized and validated method based on solid-phase extraction (SPE) and hydrophilic interaction (HILIC) LC-MS/MS (Gheorghe et al., 2008) was applied to quantify COC, BE and EME in waste water from 37 waste water treatment plants (WWTPs) and in surface water from 28 rivers and brooks across Belgium. To the best of the authors' knowledge, this is the largest monitoring study of cocaine and its metabolites in waste and surface waters up to date. The concentrations of COC and metabolites were then converted into cocaine equivalents, using the flow rate of the water stream and a formula that takes into account the molecular masses and the excretion pattern of cocaine and metabolites. The final aim was to detect regions with a high consumption of cocaine. This approach will ultimately lead to valuable information needed to tackle the growing problem of cocaine abuse in Belgium and in Europe.

\section{Materials and methods}

\subsection{Sampling sites and sample collection}

\subsubsection{Sampling sites}

WWTPs $(n=37)$ were chosen based on the amount of persons they serve and on their geographical location, so that the overall picture of cocaine use in Belgium could be made (Table 1, Fig. 1 and Fig. SI-1). Small WWTPs, which serve less than 10000 persons, were excluded from this study. The chosen WWTPs cover around 3700000 inhabitants ( $\sim 40 \%$ of the total Belgian population). Sampling sites on 28 rivers and brooks $(n=43)$ were also chosen so that they cover the whole Belgian hydrographic system (Table 2 and Fig. SI-2). Two rivers (the Demer and the Dijle) were sampled during the same day at four different downstream sites to evaluate differences in concentrations of COC and BE. One river, the Zenne, was sampled upstream and downstream of the urban region of Brussels.

\subsubsection{Sample collection}

Influent water samples (24-h flow dependent composite samples, $1.5 \mathrm{~L}$ ) were collected from WWTPs across Belgium. For each WWTP, two samples were taken, one on Sunday and one on Wednesday to evaluate differences in cocaine abuse during the week. From the WWTP of Mouscron (4 Nov 07) we received a 99-h composite sample, from Tournai (20 Jan 08) a 48-h composite sample and from Waver (18 Nov 07) a 72-h composite sample. Surface water samples (grab samples, $2.5 \mathrm{~L}$ ) were collected at 43 sampling points from 28 rivers and brooks across Belgium. All samples were collected during periods with low or no rainfall to prevent excessive dilution of analytes. Only for river Ijzer, the sampling was conducted after a heavy rainfall. For each sample, $\mathrm{pH}$ and temperature at the time of sampling were recorded.

All samples were collected in glass bottles, adjusted to $\mathrm{pH}=2$ with $37 \%$ hydrochloric acid $(\mathrm{HCl})$ and stored at $-20^{\circ} \mathrm{C}$ until analysis. The $\mathrm{pH}$ adjustment was found to be necessary to prevent degradation of $\mathrm{COC}, \mathrm{BE}$ and EME during transport and storage (Gheorghe et al., 2008). The sample collection took place from June 2007 until February 2008.

\subsection{Reagents and materials}

The compounds of interest (COC, BE and EME) and their deuterated analogues (COC- $d_{3}, \mathrm{BE}-d_{3}$ and EME- $\left.d_{3}\right)$, used as internal standards, were of analytical grade (purity $>98 \%$ ) and were purchased from Cerilliant (Round Rock, TX, USA) at concentrations of $100 \mathrm{ng} / \mu \mathrm{L}$ in methanol $(\mathrm{MeOH})$. Working mixtures of the standards with concentrations ranging between 0.01 and $10 \mathrm{ng} / \mu \mathrm{L}$ were prepared in MeOH. LCgrade acetonitrile $(\mathrm{AcN})$ and $\mathrm{MeOH}$ were purchased from Merck (Darmstadt, Germany). Milli-Q water was obtained by purifying demineralised water in a Milli-Q system (Millipore, Bedford, MA, USA). Chloric acid $(\mathrm{HCl})$ and ammonium hydroxide $\left(\mathrm{NH}_{4} \mathrm{OH}\right)$ were also obtained from Merck. Oasis $\mathrm{HLB}^{\circledR}$ SPE cartridges $(6 \mathrm{~mL}, 500 \mathrm{mg})$ were purchased from Waters (New Bedford, MA, USA). A Supelco Visiprep ${ }^{\mathrm{TM}}$ SPE Vacuum Manifold (Supelco, Bellefonte, Pennsylvania, USA) with 12 ports and a selfcleaning dry vacuum were used for the loading of water samples onto the SPE cartridges, the drying of the cartridges and the elution of analytes.

\subsection{Analytical method}

Cocaine and metabolites were analyzed in waste and surface water samples as previously described (Gheorghe et al., 2008). Before extraction, water samples (100 mL for WWTPs, $500 \mathrm{~mL}$ for rivers and brooks) were filtered over a glass microfiber filter ( $\varnothing$ $240 \mathrm{~mm}$, Macherey-Nagel, Düren, Germany) to remove solid particles. Afterwards, samples were adjusted to $\mathrm{pH}=6$ with $\mathrm{NH}_{4} \mathrm{OH}$ and then the corresponding deuterated internal standards ( $100 \mathrm{ng} \mathrm{BE}-d_{3}$ and $20 \mathrm{ng} \mathrm{COC}-d_{3}$ for waste water or $50 \mathrm{ng} \mathrm{BE}-d_{3}$ and $10 \mathrm{ng}$ COC- $d_{3}$ for surface water) were added. Oasis HLB $^{\circledR}$ cartridges, consisting of a divinylbenzene/ $N$-vinylpyrrolidone copolymer with both hydrophilic and lipophilic properties, were conditioned with $3 \mathrm{~mL}$ of $\mathrm{MeOH}$ and $3 \mathrm{~mL}$ of Milli-Q water. Samples were loaded on the cartridges at a flow rate of $3 \mathrm{~mL} / \mathrm{min}$. The cartridges were then washed with $3 \mathrm{~mL}$ of a $5 \% \mathrm{MeOH}$ in Milli-Q water solution, vacuum-dried for $15 \mathrm{~min}$ and eluted with $2 \times 4 \mathrm{~mL}$ of $\mathrm{MeOH}$. The eluates were dried under a gentle nitrogen stream and the dried samples were reconstituted in $150 \mu \mathrm{L} \mathrm{AcN} / \mathrm{MeOH}$ mixture (3/1, v/ $v)$. The reconstituted samples were filtered through modified nylon membrane $(0.45 \mu \mathrm{m}$ pore size) and centrifuged for $5 \mathrm{~min}$. The filtrate was then transferred to a glass vial for analysis.

Samples were analyzed by an Agilent 1100 series HPLC system equipped with binary pump and autosampler (Palo Alto, CA, USA), using a ZORBAX Rx-SIL HILIC column $(2.1 \mathrm{~mm} \times 150 \mathrm{~mm}, 5 \mu \mathrm{m})$ (Agilent) and a guard column with the same stationary phase. The LC was coupled to an Agilent 1100 Series MSD ion trap with electrospray ionization (ESI) operated by an HP Chemstation for MS control and spectral processing. The ESI interface was operated in positive ionization mode. MS analyses were performed in multiple reaction monitoring (MRM) mode by measuring the product ions formed by the fragmentation of the protonated pseudomolecular ions of COC, BE and EME and their internal standards.

\subsection{Quality control - quality assurance}

The method used in the present study was validated as previously described (Gheorghe et al., 2008). Calibration curves for all three compounds were generated and the intermediate precision, trueness and limit of quantification (LOQ) were determined. A summary of the method validation is given in Table SI-1. The identity for each of the investigated compounds in surface and waste water samples was confirmed through matching of retention times (relative to the standard and to the deuterated analogues used as internal standards) and on the specific MRM monitored for each analyte (Gheorghe et al., 2008).

An interlaboratory test was performed between the two participating laboratories, the Toxicological Centre (TC) in Antwerp and the Laboratory for Environmental Toxicology (LET) in Liège to evaluate the protocol used for analysis of COC, BE and EME. Nine waste water samples were exchanged and were analyzed in triplicate (for TC) or in single (for LET) following a similar protocol. Minor modifications for the analysis of $\mathrm{COC}$ and metabolites in waste and surface water were made by the LET: (i) the use of a $C_{18}$ UPLC column and (ii) the use of an UPLC-MS/MS instrument. A tap water sample spiked with $200 \mathrm{ng} / \mathrm{L} \mathrm{COC}$ and $800 \mathrm{ng} / \mathrm{L} \mathrm{BE}$ was also analyzed by the two laboratories. Table SI-2 summarizes the results for the interlaboratory test. The relative standard deviation (RSD) of the mean concentrations of COC and BE analyzed by the two laboratories was in all cases lower than the recommended cutoff value of $20 \%$ (Reed et al., 2002). This is for the first time that an interlaboratory test is reported for the analysis of COC and metabolites in waste water.

A quality control was executed during the analyses. With each batch of seven samples, a tap water sample spiked with $206 \mathrm{ng} / \mathrm{L}$ COC and $841 \mathrm{ng} / \mathrm{L}$ BE was analyzed and the recovery was calculated. Results are visualised in Figs. SI-3 and SI4. All quality controls are within the control limits of $3 \times \mathrm{SD}$, as suggested by Masson (2007).

\section{Results and discussion}

\subsection{Assumptions to calculate cocaine equivalents}

To evaluate the cocaine abuse in the selected regions, it is necessary to transform the concentrations (in ng/L) into total cocaine equivalents (in g/day) and, if possible, to further report these cocaine equivalents per 1000 inhabitants. For these calculations, different parameters which play an important role have to be known: (i) the flow rate of the water to transform concentrations of $\mathrm{COC}$ and $\mathrm{BE}$ into loads of COC and BE (expressed in g/day); (ii) the relative amount of a cocaine dose excreted as $\mathrm{COC}$ and $\mathrm{BE}$ to make a back calculation from loads COC and BE to a total amount of abused COC (in g/day); (iii) the molecular masses of the different compounds/metabolites; (iv) the stability (temperature, $\mathrm{pH}$ and time of presence in water) of COC and metabolites in aqueous matrices; and (v) the amount of inhabitants that is served by a certain WWTP.

In the literature two approaches to calculate cocaine equivalents can be found. Zuccato et al. (2005) proposed a formula based 
Table 1

Results for waste water samples

\begin{tabular}{|c|c|c|c|c|c|c|c|c|c|c|c|c|c|c|c|c|c|}
\hline \multirow[t]{2}{*}{ WWTP } & \multicolumn{2}{|c|}{ Sampling date } & \multicolumn{2}{|c|}{$\begin{array}{l}\text { Flow rate } \\
\left(\mathrm{m}^{3} / \mathrm{s}\right)\end{array}$} & \multirow[t]{2}{*}{ \# Inhabitants } & \multicolumn{2}{|c|}{$\begin{array}{l}\text { Conc. BE } \\
\text { (ng/L) }\end{array}$} & \multicolumn{2}{|c|}{$\begin{array}{l}\text { Conc. COC } \\
\text { (ng/L) }\end{array}$} & \multicolumn{2}{|c|}{$\begin{array}{l}\text { Loads BE } \\
\text { (g/day) }\end{array}$} & \multicolumn{2}{|c|}{$\begin{array}{l}\text { Loads COC } \\
\text { (g/day) }\end{array}$} & \multicolumn{2}{|c|}{$\begin{array}{l}\text { COC eq (g/day } \\
\text { per } 1000 \text { inh.) }\end{array}$} & \multicolumn{2}{|c|}{$\begin{array}{l}\text { Ratio } \\
\text { COC/BE }\end{array}$} \\
\hline & Sun & Wed & Sun & Wed & & Sun & Wed & Sun & Wed & Sun & Wed & Sun & Wed & Sun & Wed & Sun & Wed \\
\hline Aalst & $12 / 08 / 07$ & $15 / 08 / 07$ & 0.220 & 0.229 & 89847 & 322 & 455 & 92 & 128 & 6.1 & 9.0 & 1.7 & 2.5 & 0.158 & 0.233 & 0.27 & 0.27 \\
\hline Aartselaar & $26 / 08 / 07$ & $29 / 08 / 07$ & 0.228 & 0.217 & 61520 & 365 & 327 & 118 & 66 & 7.2 & 6.1 & 2.3 & 1.2 & 0.272 & 0.232 & 0.31 & 0.19 \\
\hline Antwerpen-Noord & $19 / 08 / 07$ & $29 / 08 / 07$ & 0.254 & 0.244 & 69668 & 515 & 358 & 149 & 127 & 11.3 & 7.5 & 3.3 & 2.7 & 0.377 & 0.252 & 0.28 & 0.34 \\
\hline Antwerpen-Zuid & $16 / 12 / 07$ & $05 / 12 / 07$ & 0.769 & 1.109 & 157268 & 1858 & 894 & 584 & 324 & 123.5 & 85.7 & 38.8 & 31.1 & 1.829 & 1.269 & 0.30 & 0.35 \\
\hline Arlon & $13 / 01 / 08$ & $09 / 01 / 08$ & 0.173 & 0.165 & 16043 & 351 & 315 & 117 & 71 & 5.3 & 4.5 & 1.8 & 1.0 & 0.762 & 0.653 & 0.32 & 0.21 \\
\hline Waver & $18 / 11 / 07$ & $14 / 11 / 07$ & 0.210 & 0.299 & 80000 & 248 & 149 & 60 & 28 & 4.5 & 3.9 & 1.1 & 0.7 & 0.131 & 0.112 & 0.23 & 0.18 \\
\hline Beersel & $14 / 10 / 07$ & $05 / 12 / 07$ & 0.155 & 0.333 & 63531 & 527 & 171 & 187 & 53 & 7.1 & 4.9 & 2.5 & 1.5 & 0.259 & 0.180 & 0.34 & 0.30 \\
\hline Brugge & $23 / 12 / 07$ & $03 / 10 / 07$ & 0.833 & 1.990 & 199018 & 324 & 53 & 87 & 20 & 23.3 & 9.1 & 6.3 & 3.5 & 0.298 & 0.098 & 0.26 & 0.37 \\
\hline Brussel-Noord & $16 / 12 / 07$ & $19 / 12 / 07$ & 2.932 & 2.836 & 850000 & 1291 & 909 & 348 & 273 & 327.0 & 222.7 & 88.0 & 66.8 & 0.896 & 0.610 & 0.26 & 0.29 \\
\hline Dendermonde & $28 / 10 / 07$ & $19 / 09 / 07$ & 0.184 & 0.255 & 68276 & 1221 & 504 & 230 & 110 & 19.4 & 11.1 & 3.7 & 2.4 & 0.663 & 0.379 & 0.18 & 0.21 \\
\hline Destelbergen & $14 / 10 / 07$ & $05 / 12 / 07$ & 0.155 & 0.340 & 57999 & 698 & 161 & 138 & 50 & 9.4 & 4.7 & 1.9 & 1.5 & 0.376 & 0.190 & 0.19 & 0.30 \\
\hline Deurne & $19 / 08 / 07$ & $29 / 08 / 07$ & 0.519 & 0.582 & 198569 & 2258 & 1610 & 753 & 703 & 101.3 & 80.9 & 33.8 & 35.3 & 1.189 & 0.949 & 0.32 & 0.42 \\
\hline Tournai & $20 / 01 / 08$ & $16 / 01 / 08$ & 0.214 & 0.411 & 29000 & 211 & 46 & 52 & 10 & 3.9 & 1.6 & 1.0 & 0.4 & 0.313 & 0.132 & 0.23 & 0.21 \\
\hline Genk & $16 / 12 / 07$ & $17 / 10 / 07$ & 0.504 & 0.492 & 68294 & 538 & 866 & 230 & 287 & 23.5 & 36.8 & 10.0 & 12.2 & 0.792 & 1.243 & 0.41 & 0.32 \\
\hline Gent & $12 / 08 / 07$ & $15 / 08 / 07$ & 0.601 & 0.586 & 206109 & 801 & 516 & 232 & 198 & 41.6 & 26.1 & 12.0 & 10.0 & 0.470 & 0.295 & 0.28 & 0.37 \\
\hline Harelbeke & $23 / 12 / 07$ & $26 / 09 / 07$ & 0.408 & 0.972 & 111515 & 751 & 304 & 271 & 97 & 26.5 & 25.5 & 9.6 & 8.1 & 0.553 & 0.533 & 0.34 & 0.30 \\
\hline Hasselt & $16 / 12 / 07$ & $17 / 10 / 07$ & 0.397 & 0.376 & 63333 & 402 & 467 & 134 & 126 & 13.8 & 15.2 & 4.6 & 4.1 & 0.507 & 0.559 & 0.32 & 0.26 \\
\hline Heist & $20 / 01 / 08$ & $24 / 10 / 07$ & 0.133 & 0.086 & 21196 & 296 & 716 & 80 & 141 & 3.4 & 5.3 & 0.9 & 1.1 & 0.314 & 0.718 & 0.26 & 0.19 \\
\hline Leuven & $21 / 10 / 07$ & $17 / 10 / 07$ & 0.240 & 0.395 & 113015 & 1045 & 339 & 220 & 105 & 21.6 & 11.6 & 4.6 & 3.6 & 0.446 & 0.238 & 0.20 & 0.30 \\
\hline Liedekerke & $28 / 10 / 07$ & $19 / 09 / 07$ & 0.192 & 0.258 & 92465 & 811 & 392 & 253 & 89 & 13.4 & 8.7 & 4.2 & 2.0 & 0.338 & 0.220 & 0.30 & 0.22 \\
\hline Liège & $13 / 01 / 08$ & $09 / 01 / 08$ & 0.082 & 0.118 & 26300 & 569 & 206 & 131 & 69 & 4.0 & 2.1 & 0.9 & 0.7 & 0.358 & 0.187 & 0.22 & 0.32 \\
\hline Lokeren & $12 / 08 / 07$ & $15 / 08 / 07$ & 0.198 & 0.240 & 37199 & 334 & 343 & 112 & 152 & 5.7 & 7.1 & 1.9 & 3.2 & 0.357 & 0.445 & 0.32 & 0.42 \\
\hline Mechelen-Noord & $21 / 10 / 07$ & $05 / 12 / 08$ & 0.157 & 0.450 & 87452 & 1994 & 379 & 515 & 256 & 27.1 & 14.7 & 7.0 & 9.9 & 0.721 & 0.393 & 0.25 & 0.64 \\
\hline Menen & $04 / 11 / 07$ & $26 / 09 / 07$ & 0.145 & 0.673 & 62575 & 594 & 173 & 179 & 47 & 7.4 & 10.1 & 2.2 & 2.7 & 0.277 & 0.375 & 0.29 & 0.26 \\
\hline Mol & $28 / 10 / 07$ & $12 / 12 / 08$ & 0.124 & 0.191 & 47538 & 665 & 163 & 190 & 30 & 6.8 & 2.7 & 1.9 & 0.5 & 0.332 & 0.132 & 0.27 & 0.18 \\
\hline Charleroi & $18 / 11 / 07$ & $14 / 11 / 07$ & 0.473 & 0.533 & 138000 & 994 & 839 & 370 & 242 & 40.6 & 38.6 & 15.1 & 11.1 & 0.686 & 0.652 & 0.36 & 0.28 \\
\hline Morkhoven & $28 / 10 / 07$ & $12 / 12 / 07$ & 0.078 & 0.301 & 38211 & 485 & 140 & 88 & 44 & 3.3 & 3.7 & 0.6 & 1.1 & 0.200 & 0.223 & 0.17 & 0.30 \\
\hline Mouscron & $15 / 10 / 07$ & $03 / 10 / 07$ & 0.039 & 0.200 & 27831 & 143 & 109 & 32 & 32 & 0.5 & 1.9 & 0.1 & 0.6 & 0.040 & 0.158 & 0.21 & 0.28 \\
\hline Nivelles & $16 / 12 / 07$ & $19 / 12 / 07$ & 0.167 & 0.167 & 27000 & 350 & 392 & 96 & 141 & 5.0 & 5.6 & 1.4 & 2.0 & 0.435 & 0.487 & 0.26 & 0.34 \\
\hline Oostende & $10 / 02 / 08$ & $03 / 10 / 07$ & 0.487 & 1.002 & 128822 & 312 & 181 & 121 & 57 & 10.5 & 15.9 & 4.1 & 5.0 & 0.189 & 0.290 & 0.37 & 0.30 \\
\hline Roeselare & $23 / 12 / 07$ & $26 / 09 / 07$ & 0.233 & 0.580 & 62438 & 380 & 131 & 128 & 32 & 7.7 & 6.5 & 2.6 & 1.6 & 0.285 & 0.244 & 0.32 & 0.23 \\
\hline La Louvière & $13 / 01 / 08$ & $14 / 11 / 07$ & 0.238 & 0.205 & 29800 & 328 & 156 & 95 & 38 & 6.8 & 0.7 & 2.0 & 0.7 & 0.528 & 0.217 & 0.28 & 0.23 \\
\hline Sint-Niklaas & $12 / 08 / 07$ & $15 / 08 / 07$ & 0.172 & 0.298 & 44443 & 347 & 428 & 115 & 79 & 5.2 & 11.0 & 1.7 & 2.0 & 0.270 & 0.578 & 0.32 & 0.18 \\
\hline Sint-Truiden & $16 / 12 / 07$ & $24 / 10 / 07$ & 0.291 & 0.192 & 44131 & 189 & 316 & 59 & 88 & 4.7 & 5.3 & 1.5 & 1.5 & 0.250 & 0.277 & 0.30 & 0.27 \\
\hline Mons & $18 / 11 / 07$ & $14 / 11 / 07$ & 0.095 & 0.230 & 82350 & 365 & 249 & 115 & 83 & 8.5 & 5.0 & 2.7 & 1.7 & 0.241 & 0.140 & 0.30 & 0.32 \\
\hline Verviers & $13 / 01 / 08$ & 09/01/08 & 0.716 & 0.680 & 95000 & 261 & 187 & 75 & 63 & 16.2 & 11.0 & 4.7 & 3.7 & 0.396 & 0.269 & 0.28 & 0.32 \\
\hline Wulpen & $04 / 11 / 07$ & $03 / 10 / 07$ & 0.180 & 0.237 & 43200 & 547 & 94 & 111 & 23 & 8.5 & 1.9 & 1.7 & 0.5 & 0.418 & 0.092 & 0.19 & 0.23 \\
\hline
\end{tabular}

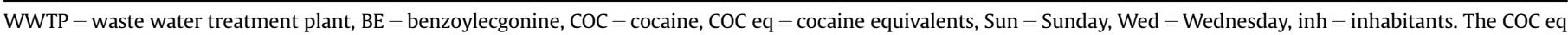
were calculated based on the following formula: $\mathrm{COC}$ eq $=2.33 \times$ loads BE, as proposed by Zuccato et al. (2005).

exclusively on BE loads. They assumed that about $45 \%$ of a cocaine dose is excreted as BE and only a small fraction as COC. Bones et al. (2007) calculated the cocaine equivalents based exclusively on COC loads and on the assumption that approximately $10 \%$ of a cocaine dose is excreted as COC. This group assumed also that $\mathrm{COC}$ is stable in waste and surface water and that the source of the $\mathrm{COC}$ found in waste and surface water comes from human excretion rather than from dumping of large quantities. The latter approach seems to be less reliable than the one proposed by Zuccato et al. (2005), since COC degraded rapidly in water, while BE is more stable (Gheorghe et al., 2008).

The above-described approaches (Bones et al., 2007; Zuccato et al., 2005) are based on several assumptions and they probably underestimate the real use of cocaine. The literature is inconsistent regarding the urinary excretion of $\mathrm{COC}$. The relative amount of a $\mathrm{COC}$ dose excreted as $\mathrm{COC}$ and BE differs strongly between various experimental setups. Between 1 and $15 \%$ of a cocaine dose is excreted as COC, while between 15 and $55 \%$ of a cocaine dose is excreted as BE (Ambre et al., 1984, 1988; Cone et al., 1998). In the future, it is necessary to develop a new mathematical model that takes every process (stability in water, urinary excretion, adsorption on solid particles) into account for a more exact estimation of the amount of cocaine abused in a certain region.

The calculation of the cocaine equivalents in Tables 1 and 2 is performed by applying the formula by Zuccato et al. (2005). In Table 1, the calculation of the cocaine equivalents per 1000 inhabitants is made.

\subsection{Cocaine and metabolites in surface water across Belgium}

Table 2 and Fig. SI-2 summarize the concentrations of $\mathrm{COC}$ and $\mathrm{BE}$ and their corresponding $\mathrm{COC}$ equivalents in surface water across Belgium. In all samples, EME was found below LOQ (20 ng/ $\mathrm{L}$ ), probably because of its low stability in water (Gheorghe et al., 2008) and its high LOQ compared to BE and COC, and therefore was not included in further calculations. $\mathrm{COC}$ and $\mathrm{BE}$ were present in surface water with a maximum of 115 and $520 \mathrm{ng} / \mathrm{L}$, respectively. For surface water, no further association between the COC equivalents and the amount of inhabitants living on the river's basin was made, since the latter cannot be estimated with accurate precision.

Generally, COC and BE levels were above LOQ in most surface water samples from Flanders (North of Belgium). Only for some smaller rivers, such as the Binchebeek and the Dommel, COC or BE was below LOQ. The absence of COC and BE in the Ijzer, a rather large river, is probably because of the massive rainfall during the sampling period (Table 2), which resulted in a high dilution of COC and BE in the surface water. Contrarily, we had a lower number of positive samples in surface water from Wallonia (South of Belgium), most probable due to the lower population density in Wallonia compared to Flanders.

The Dijle, a river that rises in Wallonia, was sampled at four different sites: Limelette, Florival, Korbeek and Wilsele (from upstream to downstream). An increasing trend in the $\mathrm{COC}$ equivalents was observed when going downstream the Dijle. This 


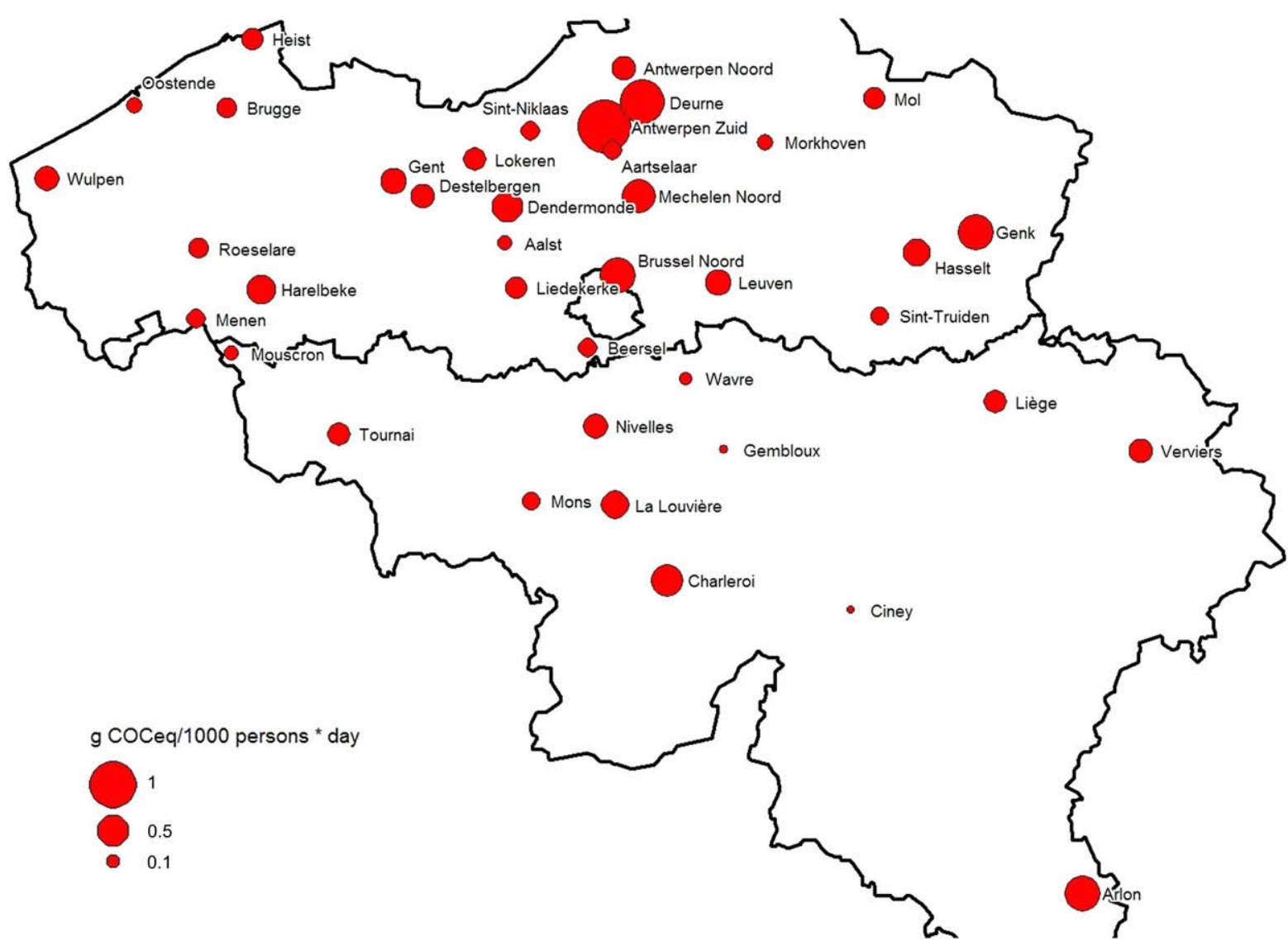

Fig. 1. Locations and results (in COC equivalents in g/day per 1000 inhabitants) of WWTP water samples collected during weekend.

observation agrees with earlier reports in other rivers (Zuccato et al., 2008) and could be explained by the continuous contamination of the rivers by waste water resulting from domestic use. Most of the domestic water runs through WWTPs, with variable removal efficiencies of COC and metabolites largely depending on the applied treatment technique (Castiglioni et al., 2006). Therefore, the effluent of the WWTPs may still contain COC and BE. Moreover, direct discharges of untreated waste water in the rivers are possible, since a large percentage of the population is not connected to a WWTP. The small drop in COC equivalents between Korbeek and Wilsele is probably a consequence of the fact that the Dijle does not receive waste water in this area and that, in the absence of additional source, the degradation of COC and BE occurs in water (Gheorghe et al., 2008). A similar trend in the COC equivalents was seen for the Demer, with the following sampling sites ranked downstream: Hasselt, Kermt, Halen and Aarschot.

Concentrations of $\mathrm{COC}$ and $\mathrm{BE}$ found in Belgian surface waters are in most cases comparable with concentrations measured in Italy (Zuccato et al., 2005, 2008), Spain (Huerta-Fontela et al., 2007) and the UK (Kasprzyk-Hordern et al., 2008a,b; Zuccato et al., 2005) (Table 3).

Since COC is transformed readily in BE in the human body, a higher concentration of $\mathrm{BE}$ than $\mathrm{COC}$ in surface water could be expected. This was confirmed by our results and results from the other studies, in which the logical pattern of higher BE concentrations than $\mathrm{COC}$ concentrations is observed. However, our results differ from those of Bones et al. (2007), who have detected COC in surface water without being able to measure BE in most cases. Therefore, this is a remarkable (if not questionable) finding which has been partially explained by Bones et al. through the use of a different sample preparation technique.

The mean \pm SD ratio COC/BE for the surface water samples was $0.18 \pm 0.11$ and no outliers were observed. This value agrees well with values reported for urinary excretion of $\mathrm{BE}$ and $\mathrm{COC}$ (mean $8 \%$ COC, 35\% BE; COC/BE = 0.23) (Ambre et al., 1984, 1988; Cone et al., 1998). The relatively high RSD (60\%) is a consequence of the very broad ranges of urinary excretion of $\mathrm{COC}$ and $\mathrm{BE}$ reported in the literature. Our findings are comparable with, but yet higher than the ratio measured by Zuccato et al. (2005) in the Po river (0.05), probably attributed to different temperatures of river Po and the rivers sampled in the present study, resulting in a different degradation pattern of $\mathrm{COC}$ and BE.

The concentrations of $\mathrm{BE}$ and $\mathrm{COC}$ in the river Zenne at Vilvoorde (downstream of Brussels) are well above the levels observed in other Belgian rivers (this study) and in other European rivers (Table 3 ). The river Zenne still receives directly a large amount of industrial and domestic untreated waste water from Brussels, which explains the high concentrations of $\mathrm{COC}$ and $\mathrm{BE}$ observed downstream of Brussels. This hypothesis is confirmed by the low levels of $\mathrm{COC}$ and BE measured in the surface water collected on the same day from river Zenne in Lot (upstream of Brussels) (Table 2), which suggests that indeed the urban agglomeration of Brussels is responsible for the dramatic increase in concentrations of $\mathrm{COC}$ and $\mathrm{BE}$ in the water of river Zenne.

\subsection{Cocaine and metabolites in waste water across Belgium}

$\mathrm{COC}$ and BE were quantifiable in all waste water samples collected from WWTPs spread across Belgium (Table 1 and Fig. 1 and Fig. SI-1). Similar to surface water, EME was below LOQ (20 ng/L) in all WWTP samples. It is worth mentioning that EME was neither reported nor measured in WWTP samples until now. The concentration ranges of $C O C$ and BE in the influent WWTP water samples were 10-753 ng/L and 33-2258 ng/L, respectively. 
Table 2

Results for surface water samples

\begin{tabular}{|c|c|c|c|c|c|c|c|c|c|}
\hline River & Town/village & $\begin{array}{l}\text { Sampling } \\
\text { date }\end{array}$ & $\begin{array}{l}\text { Flow rate } \\
\left(\mathrm{m}^{3} / \mathrm{s}\right)\end{array}$ & $\begin{array}{l}\text { Concentration BE } \\
(\mathrm{ng} / \mathrm{L})\end{array}$ & $\begin{array}{l}\text { Concentration } \mathrm{COC} \\
(\mathrm{ng} / \mathrm{L})\end{array}$ & $\begin{array}{l}\text { Loads BE } \\
\text { (g/day) }\end{array}$ & $\begin{array}{l}\text { Loads COC } \\
\text { (g/day) }\end{array}$ & COC eq (g/day) & $\overline{\text { Ratio } \mathrm{COC} / \mathrm{BE}}$ \\
\hline$\overline{\mathrm{Aa}}$ & Oud-Turnhout & $27 / 06 / 07$ & 0.841 & 8.6 & 4.1 & 0.6 & 0.3 & 0.46 & 1.453 \\
\hline Aa & Poederlee & $27 / 06 / 07$ & 2.500 & 10.1 & 1.2 & 2.2 & 0. & 0.11 & 5.065 \\
\hline Amblève & Martinrive & $12 / 10 / 07$ & 8.726 & $<0.5$ & $<1$ & - & - & - & - \\
\hline Bellebeek & Ternat & $10 / 06 / 07$ & 0.125 & 75.1 & 12.2 & 0.8 & 0.1 & 0.15 & 1.889 \\
\hline Binchebeek & Geraardsbergen & $27 / 07 / 07$ & $\mathrm{~nm}$ & $<0.5$ & $<1$ & - & - & - & - \\
\hline Demer & Halen & $26 / 07 / 07$ & 2.100 & 47.6 & 12.6 & 8.6 & 2.3 & 0.25 & 20.098 \\
\hline Demer & Aarschot & $26 / 0707$ & 9.079 & 38.5 & 7.6 & 30.2 & 6.0 & 0.19 & 70.316 \\
\hline Demer & Hasselt & $26 / 07 / 07$ & 1.281 & 44.3 & 13.2 & 4.9 & 1.5 & 0.28 & 11.415 \\
\hline Demer & Kermt & $26 / 07 / 07$ & 3.515 & 32.2 & 8.3 & 9.8 & 2.5 & 0.25 & 22.813 \\
\hline Dender & Overboelare & $10 / 06 / 07$ & 1.555 & 23.4 & 3.0 & 3.2 & 0.4 & 0.12 & 7.337 \\
\hline Dender & Dendermonde & $27 / 07 / 07$ & 0.613 & 8.1 & $<1$ & 0.4 & - & - & 1.002 \\
\hline Dendre Occ. & Ligne & $27 / 07 / 07$ & 0.234 & 2.3 & $<1$ & 0.1 & - & - & 0.106 \\
\hline Dijle & Wilsele & $17 / 07 / 07$ & 9.698 & 27.6 & 2.2 & 23.1 & 1.8 & 0.08 & 53.881 \\
\hline Dijle & Korbeek & $17 / 07 / 07$ & 9.98 & 34.2 & 5.8 & 29.5 & 5.0 & 0.16 & 68.702 \\
\hline Dijle & Limelette & $26 / 07 / 07$ & 2.787 & 21.5 & 2.4 & 5.19 & 0.6 & 0.10 & 12.083 \\
\hline Dijle & Florival & $17 / 07 / 07$ & 2.940 & 23.9 & 3.1 & 6.1 & 0.8 & 0.12 & 14.143 \\
\hline Dommel & Neerpelt & $17 / 07 / 07$ & 1.085 & $<0.5$ & $<1$ & - & - & - & - \\
\hline Grote Molenbeek & Sint-Amands & $22 / 06 / 07$ & 0.219 & 190.5 & 26.2 & 3.6 & 0.5 & 0.13 & 8.397 \\
\hline Grote Nete & Hulshout & $27 / 06 / 07$ & 5.414 & 8.2 & 1.2 & 3.9 & 0.6 & 0.14 & 8.988 \\
\hline Grote Nete & Geel & $27 / 06 / 07$ & 9.276 & 9.3 & 5.4 & 7.5 & 4.3 & 0.55 & 17.449 \\
\hline Hain & $\begin{array}{l}\text { Braine-le- } \\
\text { Château }\end{array}$ & $27 / 07 / 07$ & 0.256 & 151.2 & 26.7 & 3.3 & 0.6 & 0.17 & 7.790 \\
\hline Herk & Wellen & $06 / 07 / 07$ & 0.450 & 18.4 & 2.5 & 0.7 & 0.1 & 0.13 & 1.666 \\
\hline Ieperlee & Zuidschotte & $10 / 10 / 07$ & 1.041 & 6.6 & $<1$ & 0.6 & - & - & 1.393 \\
\hline Ijzer & Roesbrugge & $10 / 10 / 07$ & 13.203 & $<0.5$ & $<1$ & - & - & - & - \\
\hline Ijzer & Keiem & $10 / 10 / 07$ & 24.345 & $<0.5$ & $<1$ & - & - & - & - \\
\hline Kleine Nete & Grobbendonk & $19 / 06 / 07$ & 3.764 & 15.5 & 2.3 & 5.0 & 0.8 & 0.14 & 11.749 \\
\hline Leie & Deinze & $02 / 08 / 07$ & 2.068 & 5.1 & $<1$ & 0.9 & - & - & 2.105 \\
\hline Leie & Menen & $03 / 08 / 07$ & 18.305 & 8.8 & $<1$ & 14.0 & - & - & 32.603 \\
\hline Lesse & Gendron & $11 / 10 / 07$ & 5.610 & $<0.5$ & $<1$ & - & - & - & - \\
\hline Maas & Lanaken & $12 / 10 / 07$ & 60.000 & 18.9 & 2.0 & 5.1 & 0.5 & 0.10 & 227.884 \\
\hline Maas & Maaseik & $11 / 10 / 07$ & 60.000 & 12.2 & 1.1 & 63.3 & 5.7 & 0.07 & 147.516 \\
\hline Ourthe & Tabreux & $12 / 10 / 07$ & 7.668 & $<0.5$ & $<1$ & - & - & - & - \\
\hline Petite Gette & Opheylissem & $17 / 07 / 07$ & 0.535 & 22.4 & 4.0 & 1.0 & 0.2 & 0.17 & 2.410 \\
\hline Rivierbeek & Oostkamp & $02 / 08 / 07$ & 0.316 & 5.0 & $<1$ & 0.1 & - & - & 0.316 \\
\hline Sambre & Solre & $12 / 10 / 07$ & 5.330 & 3.5 & $<1$ & 1.6 & - & - & 3.799 \\
\hline Semois & Membre & $18 / 10 / 07$ & 4.946 & $<0.5$ & $<1$ & - & - & - & - \\
\hline Semois & Chiny & $18 / 10 / 07$ & 2.809 & $<0.5$ & $<1$ & - & - & - & - \\
\hline Senette & Ronquières & $27 / 07 / 07$ & 0.135 & 53.0 & 7.4 & 0.6 & 0.1 & 0.13 & 1.440 \\
\hline Viroin & Treignes & $12 / 10 / 07$ & 1.876 & $<0.5$ & $<1$ & - & - & - & - \\
\hline Zeeschelde & Melle & $02 / 08 / 07$ & 41.500 & 10.8 & $<1$ & 38.6 & - & - & 89.974 \\
\hline Zenne & Lot & $09 / 07 / 07$ & 3.652 & 69.0 & 13.0 & 23.3 & 3.7 & 0.18 & 50.601 \\
\hline Zenne & Vilvoorde & $09 / 07 / 07$ & 5.555 & 520.2 & 114.9 & 249.7 & 55.2 & 0.21 & 581.665 \\
\hline Zuunbeek & Sint-Pietersleeuw & $09 / 07 / 07$ & 0.050 & 75.1 & 14.4 & 0.3 & 0.1 & 0.18 & 0.756 \\
\hline
\end{tabular}

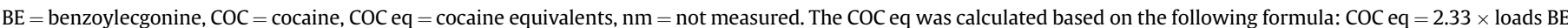
as proposed by Zuccato et al. (2005).

Every WWTP was sampled twice, on Wednesday and on Sunday, with the purpose to investigate differences in the abuse of cocaine throughout the week. Cocaine abuse was significantly higher ( $p=0.018$, paired samples $t$-test) during the weekend compared with the week (the average difference was $0.08 \mathrm{~g} /$ day per 1000 inhabitants). For some WWTPs, there were no clear differences between the COC equivalents calculated between the two days and this could be explained by a wide variety of factors. For instance, for Mouscron WWTP we received a 99-h composite sample, which means that waste water from four consecutive days was collected, compared to the 24-h samples collected for the other WWTPs. Due to expected tourist activities at the North Sea, the concentrations of BE and COC in WWTP samples from Oostende and Heist are susceptible to large fluctuations which strongly depend on holiday periods. For the other WWTP samples, we could not find a proper explanation, but following factors could play a role: (i) local parties or small festivals; (ii) size and location of the WWTP; (iii) more regular cocaine consumers than recreational users.

The highest $\mathrm{COC}$ equivalents can be found in Antwerpen-Zuid, Deurne and Brussel-Noord WWTPs, with weekend COC equivalents of $1.8,1.2$, and $0.9 \mathrm{~g} / 1000$ inhabitants, respectively.

For the city of Antwerp, we have sampled three WWTPs (Fig. SI5). The Antwerpen-Zuid and Deurne WWTPs receive waste water from the centre of Antwerp and from surrounding suburbs, while Antwerpen-Noord WWTP receives only waste water from the northern suburbs (Fig. SI-5). As expected, higher COC equivalents were calculated in the waste water samples from Antwerpen-Zuid and Deurne WWTPs (Table 1). This is most probably due to two reasons: (i) these WWTPs receive waste water from the centre of Antwerp and (ii) a different social standard, more reported criminality and drug traffic in the suburbs whose waste water ends up in Antwerpen-Zuid and Deurne WWTPs compared to AntwerpenNoord WWTP.

For Brussel-Noord WWTP, four 24-h composite samples were collected within the same week, on Friday, Saturday, Sunday and the following Wednesday, to evaluate possible daily variations in the cocaine equivalents (Table 4). As expected, we observed a clear peak in the COC equivalents during the weekend. Since it takes approximately $24 \mathrm{~h}$ for water to run from the domestic site to a WWTP (personal communication, Alain Vandelannoote, Aquafin), it means that the cocaine abuse on Friday is detected in the samples collected on Saturday. After intake, COC can be measured in urine up to $6 \mathrm{~h}$, while BE is excreted over a larger period (up to 96 h) (Hamilton et al., 1977; Jufer et al., 2000). Therefore, samples from Sunday would still contain traces of BE originating from cocaine abuse on Friday. This explains the increasing BE loads 
Table 3

Concentrations of BE and COC of other studies

\begin{tabular}{|c|c|c|c|c|c|c|}
\hline \multirow{2}{*}{$\frac{\text { Place }}{\text { Olona, IT }}$} & \multirow{2}{*}{$\begin{array}{l}\text { Type } \\
\text { Surface }\end{array}$} & \multicolumn{2}{|l|}{ Conc. BE (ng/L) } & \multicolumn{2}{|c|}{ Conc. COC (ng/L) } & \multirow{2}{*}{$\begin{array}{l}\text { Reference } \\
\text { Zuccato et al. (2008) }\end{array}$} \\
\hline & & & & & & \\
\hline & & 183 & & 44 & & \\
\hline \multirow[t]{2}{*}{ Lambro, IT } & Surface & & & & & Zuccato et al. (2008) \\
\hline & & 50 & & 15 & & \\
\hline \multirow[t]{2}{*}{ Po, IT } & Surface & & & & & Zuccato et al. (2008) \\
\hline & & 4 & & 1 & & \\
\hline \multirow[t]{2}{*}{ Arno, IT } & Surface & & & & & Zuccato et al. (2008) \\
\hline & & 22 & & 2 & & \\
\hline \multirow[t]{2}{*}{ Thames, UK } & Surface & & & & & Zuccato et al. (2008) \\
\hline & & 13 & & 4 & & \\
\hline \multirow[t]{2}{*}{ Po, IT } & Surface & & & & & Zuccato et al. (2005) \\
\hline & & 25 & & 1 & & \\
\hline \multirow[t]{2}{*}{ Taff, UK } & Surface & & & & & Kasprzyk-Hordern et al. (2008a) \\
\hline & & 78 & & 2 & & \\
\hline \multirow{2}{*}{ Ely, UK } & Surface & & & & & Kasprzyk-Hordern et al. (2008b) \\
\hline & & 23 & & $<0.3$ & & \\
\hline \multirow[t]{2}{*}{ Broadmeadow, RI } & Surface & nd & & & & Bones et al. (2007) \\
\hline & & & & 25 & & \\
\hline \multirow[t]{2}{*}{ Llobregat, ES } & Surface & & & & & Huerta-Fontela et al. (2007) \\
\hline & & 77 & & 6 & & \\
\hline \multirow[t]{5}{*}{$\mathrm{BE}$} & Surface & Min & 1 & Min & 1 & Present study \\
\hline & & Max & 520 & Max & 115 & \\
\hline & & Mean & 37 & Mean & 7 & \\
\hline & & Median & 11 & Median & 2 & \\
\hline & & SD & 85 & SD & 18 & \\
\hline \multirow[t]{2}{*}{ Ringsend, RI } & Waste & & & & & Bones et al. (2007) \\
\hline & & 290 & & 489 & & \\
\hline \multirow[t]{2}{*}{ Spain, ES } & Waste & & & & & Huerta-Fontela et al. (2007) \\
\hline & & 810 & & 79 & & \\
\hline \multirow[t]{2}{*}{ Nosedo, IT } & Waste & & & & & Castiglioni et al. (2006) \\
\hline & & 1132 & & 421 & & \\
\hline \multirow[t]{2}{*}{ Lugano, $\mathrm{CH}$} & Waste & & & & & Castiglioni et al. (2006) \\
\hline & & 547 & & 218 & & \\
\hline \multirow[t]{2}{*}{ Cagliari, IT } & Waste & & & & & Zuccato et al. (2005) \\
\hline & & 640 & & 83 & & \\
\hline \multirow[t]{2}{*}{ Cuneo, IT } & Waste & & & & & Zuccato et al. (2005) \\
\hline & & 420 & & 76 & & \\
\hline Latina, IT & Waste & & & & & Zuccato et al. (2005) \\
\hline & & 750 & & 120 & & \\
\hline Cilfynydd, UK & Waste & & & & & Kasprzyk-Hordern et al. (2008a) \\
\hline & & 1229 & & 526 & & \\
\hline Varese, IT & Waste & & & & & Zuccato et al. (2005) \\
\hline & & 390 & & 42 & & \\
\hline $\mathrm{BE}$ & Waste & Min & 33 & Min & 10 & Present study \\
\hline & & Max & 2258 & Max & 753 & \\
\hline & & Mean & 497 & Mean & 146 & \\
\hline & & Median & 351 & Median & 110 & \\
\hline & & SD & 440 & SD & 141 & \\
\hline
\end{tabular}

IT: Italy, UK: United Kingdom, RI: Republic of Ireland, ES: Spain, BE: Belgium, CH: Switzerland.

throughout the weekend and the peak in COC loads observed on Saturday.

The concentrations and ratios of $\mathrm{COC}$ and $\mathrm{BE}$ observed in the present study are comparable to the results from Italian (Castiglioni et al., 2006; Zuccato et al., 2005, 2008), Spanish (Huerta-Fontela et al., 2007), and UK WWTPs (Kasprzyk-Hordern et al., 2008a,b; Zuccato et al., 2005) (Table 3). As hypothesized from the urinary

Table 4

Results for WWTP Brussel-Noord

\begin{tabular}{|c|c|c|c|c|c|c|}
\hline Day & $\begin{array}{l}\text { Conc. BE } \\
\text { (ng/L) }\end{array}$ & $\begin{array}{l}\text { Conc. COC } \\
\text { (ng/L) }\end{array}$ & $\begin{array}{l}\text { Loads BE } \\
\text { (g/day) }\end{array}$ & $\begin{array}{l}\text { Loads COC } \\
\text { (g/day) }\end{array}$ & $\begin{array}{l}\text { COC eq } \\
\text { (g/day) }\end{array}$ & $\begin{array}{l}\text { COC eq/1000 } \\
\text { inh. (g/day) }\end{array}$ \\
\hline Fri $14 / 12 / 2007$ & 856 & 221 & 232.3 & 59.9 & 601.3 & 0.707 \\
\hline Sat $15 / 12 / 2007$ & 1157 & 362 & 292.7 & 91.5 & 773.5 & 0.910 \\
\hline Sun $16 / 12 / 2007$ & 1291 & 348 & 327.0 & 88.0 & 849.9 & 0.999 \\
\hline Wed $19 / 12 / 2007$ & 909 & 274 & 222.7 & 66.8 & 585.6 & 0.689 \\
\hline
\end{tabular}

inh $=$ inhabitants excretion pattern, higher BE concentrations than COC concentrations were found in waste water. However, Bones et al. (2007) measured higher levels of COC than BE in Irish waste water, which conflicts with the normal expected pattern resulting from the metabolism of cocaine.

The mean $\pm S D$ ratio $C O C / B E$ in waste water samples was $0.28 \pm 0.07$ and no outliers were observed. This ratio is comparable with the mean value $(0.23)$ resulting from averaging the percentages of urinary excretion of BE and COC (Ambre et al., 1984, 1988; Cone et al., 1998). The calculated RSD (26\%) is a consequence of the broad ranges of urinary excretion of $\mathrm{COC}$ and $\mathrm{BE}$ reported in the literature and of the differences in the stability of $\mathrm{COC}$ and BE in aquatic systems (Gheorghe et al., 2008). Yet, the RSD for waste water is lower than for surface water, indicating that for surface water, more factors, such as weather conditions, time of residence and turbidity, are responsible for the observed variations. The ratio COC/BE in waste water was higher than in surface water. The longer presence of $\mathrm{COC}$ and $\mathrm{BE}$ in surface water and the instability of $\mathrm{COC}$ in water are 
possibly an explanation for this observed difference. Such difference between the $\mathrm{COC} / \mathrm{BE}$ ratios in waste and surface water samples agrees with the difference observed by Zuccato et al. (2005).

\section{Conclusions}

The present study offers for the first time a deeper insight in the daily/weekly variation of $\mathrm{COC}$ and its major metabolite, BE, in a large number of waste and surface water samples collected throughout whole Belgium. The detection of COC and BE in all waste water samples indicates a widespread abuse and emphasizes that such monitoring is important to get a better view on the growing issue of cocaine. The present approach of estimating cocaine use could be executed on a regular basis for short term (monthly) to long term (yearly) monitoring and gives an immediate and clear picture of the geographical variation in cocaine abuse. This information will ultimately serve to setup prevention campaigns in the regions with high cocaine abuse, while the regular analysis of waste water can quickly evaluate the effect of these prevention campaigns. Future assessments of cocaine abuse through analysis of waste water should include more accurate mathematical models which need to include various factors such as urinary excretion profiles, stability of $\mathrm{COC}$ and metabolites in water and adsorption on solid particles.

\section{Acknowledgements}

Alexander van Nuijs is grateful to the University of Antwerp for his PhD scholarship. Bert Pecceu and Laetitia Theunis acknowledge the Belgian government and the Belgian Science Policy (Belspo) for their financial support (COWAT project DR 00-0047). Adrian Covaci acknowledges the financial support granted by a postdoctoral fellowship by Flanders Scientific Funds for Research (FWO). The authors are grateful to all the WWTP for the permission to collect the water samples.

\section{Appendix. Supplementary data}

Results of waste water samples taken on Wednesdays are visualised in Fig. SI-1. Sampling locations and results of surface water are presented in Fig. SI-2. Details and results of the method validation and the interlaboratory test are described in Tables SI-1 and SI-2, respectively. Quality control charts for COC and BE are given in Figs. SI-3 and SI-4, respectively. Fig. SI-5 gives a geographical situation of the three sample WWTPs from Antwerp. Supplementary data associated with this article can be found in the online version at doi:10.1016/j.envpol.2008.07.020.

\section{References}

Ambre, J., Fischman, M., Ruo, T., 1984. Urinary excretion of ecgonine methyl ester, a major metabolite of cocaine in humans. Journal of Analytical Toxicology 8, 23-25.
Ambre, J., Ruo, T., Nelson, J., Belknap, S., 1988. Urinary excretion of cocaine, benzoylecgonine and ecgonine methyl ester in humans. Journal of Analytical Toxicology 12, 301-306.

Bones, J., Thomas, K.V., Paull, B., 2007. Using environmental analytical data to estimate levels of community consumption of illicit drugs and abused pharmaceuticals. Journal of Environmental Monitoring 9, 701-707.

Castiglioni, S., Zuccato, E., Crisci, E., Chiabrando, C., Fanelli, R., Bagnati, R., 2006. Identification and measurement of illicit drugs and their metabolites in urban wastewater by liquid chromatography-tandem mass spectrometry. Analytical Chemistry 78, 8421-8429.

Cone, E.J., 1995. Pharmacokinetics and pharmacodynamics of cocaine. Journal of Analytical Toxicology 19, 459-478.

Cone, E.J., Tsadik, A., Oyler, J., Darwin, W.D., 1998. Cocaine metabolism and urinary excretion after different routes of administration. Therapeutic Drug Monitoring 20, 556-560.

Dart, R.C., 2004. Medical Toxicology, third ed. Lippincott, Williams and Wilkins, Baltimore, MD.

European Monitoring Centre for Drugs and Drug Addiction (EMCDDA), 2007. The State of the Drug Problem in the European Union and Norway. Annual Report 2007. EMCDDA, Lisbon, Portugal. Available from: htttp://www.emcdda.europa. eu/attachements.cfm/att_42156_EN_TDAC07001ENC.pdf.

European Monitoring Centre for Drugs and Drug Addiction (EMCDDA), 2002. EMCDDA Project CT.99.EP.08 B. Handbook for Surveys on Drug Use among the General Population. EMCDDA, Lisbon, Portugal. Available from: http://www. emcdda.eu.int/?fuseaction = public.AttachmentDownload\&nNodeID=1390.

Gheorghe, A., van Nuijs, A., Pecceu, B., Bervoets, L., Jorens, P.G., Blust, R., Neels, H., Covaci, A., 2008. Analysis of cocaine and its principal metabolites in waste and surface water using solid-phase extraction and liquid chromatography-ion trap tandem mass spectrometry. Analytical and Bioanalytical Chemistry 391, 13091319.

Hamilton, H.E., Wallace, J.E., Shimek Jr., E.L., Land, P., Harris, S.C., Christenson, J.G., 1977. Cocaine and benzoylecgonine excretion in humans. Journal of Forensic Sciences 22, 697-707.

Huerta-Fontela, M., Galceran, M.T., Ventura, F., 2007. Ultraperformance liquid chromatography-tandem mass spectrometry analysis of stimulatory drugs of abuse in wastewater and surface waters. Analytical Chemistry 79, 3821-3829.

Hummel, D., Löffler, D., Fink, D., Ternes, T.A., 2006. Simultaneous determination of psychoactive drugs and their metabolites in aqueous matrices by liquid chromatography mass spectrometry. Environmental Science and Technology 40, 7321-7328.

Jufer, R.A., Wstadik, A., Walsh, S.L., Levine, B.S., Cone, E.J., 2000. Elimination of cocaine and metabolites in plasma, saliva, and urine following repeated oral administration to human volunteers. Journal of Analytical Toxicology 24, 467-477.

Kasprzyk-Hordern, B., Dinsdale, R.M., Guwy, A.J., 2008a. Multiresidue methods for the analysis of pharmaceuticals, personal care products and illicit drugs in surface water and wastewater by solid-phase extraction and ultra performance liquid chromatography-electrospray tandem mass spectrometry. Analytical and Bioanalytical Chemistry 391, 1293-1308.

Kasprzyk-Hordern, B., Dinsdale, R.M., Guwy, A.J., 2008b. The occurrence of pharmaceuticals, personal care products, endocrine disruptors and illicit drugs in surface water in South Wales, UK. Water Research 42, 3498-3518.

Lakoski, J.M., Galloway, M.P., White, F.J., 1991. Cocaine: Pharmacology, Physiology and Clinical Strategies. CRC Press, Boca Raton.

Lamkaddem, B., Roelands, M., 2007. Belgian National Report on Drugs 2007. Scientific Institute of Public Health, Epidemiology Unit, Brussels, Belgium.

Masson, P., 2007. Quality control techniques for routine analysis with liquid chromatography in laboratories. Journal of Chromatography A 1158, 168-173.

Reed, G.F., Lynn, F., Meade, B.D., 2002. Use of coefficient of variation in assessing variability of quantitative assays. Clinical and Diagnostic Laboratory Immunology 9, 1235-1239.

Zuccato, E., Castiglioni, S., Bagnati, R., Chiabrando, C., Grassi, P., Fanelli, R., 2008. Illicit drugs, a novel group of environmental contaminants. Water Research 42, 961-968.

Zuccato, E., Chiabrando, C., Castiglioni, S., Calamari, D., Bagnati, R., Schiarea, S., Fanelli, R., 2005. Cocaine in surface waters: a new evidence-based tool to monitor community drug abuse. Environmental Health: A Global Access Science Source 4, 14-20. 